This item was submitted to Loughborough's Research Repository by the author.

Items in Figshare are protected by copyright, with all rights reserved, unless otherwise indicated.

\title{
Multi-parameter flow cytometry and cell sorting reveal extensive physiological heterogeneity in Bacillus cereus batch cultures.
}

PLEASE CITE THE PUBLISHED VERSION

http://dx.doi.org/10.1007/s10529-011-0566-z

PUBLISHER

(C) Springer

VERSION

AM (Accepted Manuscript)

LICENCE

CC BY-NC-ND 4.0

\section{REPOSITORY RECORD}

Want, Andrew, Helen Hancocks, Stuart M. Stocks, Gerhard Nebe-von-Caron, and Christopher J. Hewitt. 2011. "Multi-parameter Flow Cytometry and Cell Sorting Reveal Extensive Physiological Heterogeneity in Bacillus Cereus Batch Cultures.”. figshare. https://hdl.handle.net/2134/8617. 
This item was submitted to Loughborough's Institutional Repository (https://dspace.lboro.ac.uk/) by the author and is made available under the following Creative Commons Licence conditions.

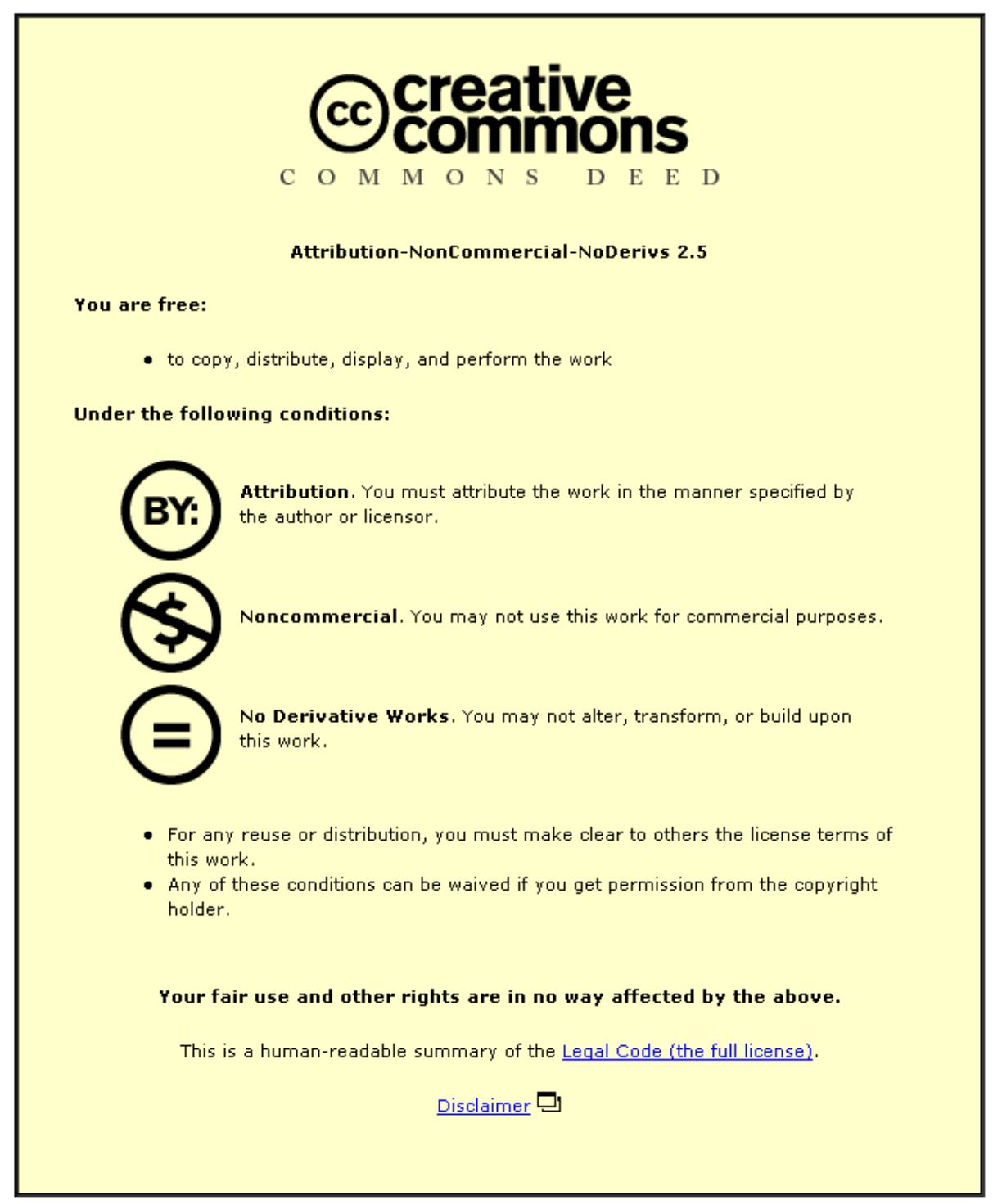

For the full text of this licence, please go to: http://creativecommons.org/licenses/by-nc-nd/2.5/ 


\title{
Multi-parameter flow cytometry and cell sorting reveal extreme physiological heterogeneity in Bacillus cereus batch cultures.
}

Running title: Flow cytometry and cell sorting on B. cereus cultures

Contents category: Physiology and Biochemistry

\author{
Andrew Want ${ }^{1}$, Helen Hancocks ${ }^{2}$, Colin R. Thomas ${ }^{2}$, Stuart M. Stocks ${ }^{3}$, Gerhard \\ Nebe-von-Caron ${ }^{4}$ and Christopher J. Hewitt ${ }^{1}$
}

${ }^{I}$ Centre for Biological Engineering, Department of Chemical Engineering, Loughborough University, Leicestershire, LE11 3TU, UK

${ }^{2}$ Centre for Bioprocess Engineering, School of Chemical Engineering, The University of Birmingham, Edgbaston, B15 2TT, UK.

${ }^{3}$ Novozymes A/S, Smørmosevej 25 (2JS.12), 2880 Bagsvard, DENMARK

${ }^{4}$ Inverness Medical International, Priory Business Park, Bedford, MK44 3UP, UK

*Author for correspondence. E-mail: c.j.hewitt@lboro.ac.uk)

Keywords: bacteria, flow cytometry, membrane potential, membrane integrity, propidium iodide, 3,3'-dihexylocarbocyanine iodide, bis-(1, 3-dibutylbarbituric acid) trimethine oxonol 


\section{ABSTRACT}

Here we tried to develop a standard flow cytometry protocol for measuring the physiological state of the Gram +'ve bacterium Bacillus cereus, and attempted to understand more of the resulting staining phenomena using cell sorting. Specifically the use of $\mathrm{DiOC}_{6}(3)$ and the proprietary RedoxSensor Green ${ }^{\mathrm{TM}}$ (an indicator of bacterial reductase activity) both counter stained with propidium iodide. The data presented here has identified at least 4 distinguishable physiological states based on the two staining protocols alone and dependent on the position in the growth cycle single cells gave rise to varying numbers of colonies when sorted individually onto nutrient agar plates. Further that these growing colonies derived from single cell sorts had widely different lag phases. This highlights further the unexpectedly complex population dynamics of bacterial cultures and lays to rest the microbiological dogma that all bacterial cells in a culture behave in exactly the same way since they are clearly members of a physiologically heterogenous and dynamic population.

\section{INTRODUCTION}

Multi-parameter flow cytometry has many advantages over conventional microbiological analyses such as dilution plating (c.f.u. per ml) and these have been extensively reviewed elsewhere (Nebe-con-Caron et al., 2000; Hewitt \& Nebe-von-Caron 2001, 2004) but briefly, using various mixtures of fluorescent dyes, it is possible to resolve an individual microbial cell's physiological state beyond culturabilty, in 'real-time' based on the presence or absence of an intact polarised cytoplasmic membrane and the transport mechanisms across it. The presence of both an intact polarised cytoplasmic membrane and active transport systems across it are essential for a fully functional healthy cell. The cytoplasmic membrane potential (CMP) of prokaryotes is between $100-200 \mathrm{mV}$, the exact 
magnitude depending on the physiological state of the cell with the inside of the cell negative with respect to its exterior (Shapiro 2003). In general Gram -ve cells have a higher maximum CMP than Gram +ve cells so anionic stains such as bis-(1, 3-dibutylbarbituric acid) trimethine oxonol (bis-oxonol) are often used (Jepras et al., 1997; Hewitt et al., 1998) to reflect CMP in preference to fluorescent probes that are accumulated actively (e.g. Rhodamine 123). This is because Gram -ve bacteria, like E. coli, frequently do not take up cationic stains unless the outer membrane of the cell is permeablised (e.g. by repeatedly washing with an EDTA solution (Hewitt et al., 1998)). Therefore it is not known if any subsequent staining reflects the true CMP at the time of sampling or whether it is an artefact due to the treatment regime employed (Davey \& Kell 1996). This can be further complicated if active transport systems exist that pump the fluorescent stain out of the cell, since interference with or from such transport systems will obviously influence CMP (Nebe-von-Caron \& Badley 1995).

In theory distributional probes should distribute themselves as described in the Nernst equation,

$$
\psi_{i}-\psi_{o}=\frac{R T}{z F} \times \ln \left(\frac{a_{o}}{a_{i}}\right) \quad \text { Equation } 1
$$

However, theory and practise are often not in perfect alignment. In the case of cationic probes such as Rhodamine 123, potential based staining is perceived to be reduced at high dye concentrations, leading to indistinguishable dye uptake in polarised and depolarised cells (Nebe-von-Caron \& Mueller 2007). For anionic probes an increase in target sites even with low level uptake of dye can lead to accumulation of dye intracellularly. Thus if the CMP does not overcome the affinity of the probe to the intracellular target or a temporary 'leakage' across the cytoplasmic membrane exists, the dye accumulates inside the cell. The control applied to test for CMP independent accumulation of a dye is to collapse the CMP 
using decouplers (Hewitt et al., 1999). However, this method fails if the cells do not stain because of their outer membrane or active dye export or because of uptake due to temporary 'leakiness'. In those cases the best control is to attempt staining with a CMP probe of the opposite charge.

In the case of a Gram +ve Rhodococcus sp. only $\sim 40 \%$ of the cell population showed exclusion of bis-oxonol during nutrient sufficient conditions (Hewitt \& Nebe-von-Caron 2004). Since it is unlikely for the cells not to possess a CMP during exponential growth this indicates that the uptake of bis-oxonol in this case does not reflect the complete collapse of the CMP. Additionally, the cells still excluded propidium iodide, indicating that a certain degree of cytoplasmic membrane integrity remained. Such counter intuitive phenomena are not unique, PI straining during exponential phase has been observed in actinomycetes (Sebastine et al., 1999; Stocks \& Thomas 2001) and mycobacteria (Shi et al., 2007). While it may be possible to construct explanations for the reasons that "live" cells fail to stain -'ve with bis-oxanol, or can stain +'ve with PI, one must also consider that such populations contain cells which are in fact CMP negative, with intact membranes, or that there can be a minimum in "viability" during exponential growth.

There are also obvious differences between Gram +'ve and -'ve organisms, precisely in their membrane architectures. The cationic stain 3,3'-dihexylocarbocyanine iodide $\mathrm{DiOC}_{6}(3)$ that accumulates actively (i.e. that enter and stain the cell when the cytoplasmic membrane is polarised) was seen to be preferential for reflecting changes in CMP for Gram +ve organisms (Müller et al., 1996; Lopes da Silva et al., 2005) especially since they do not have to cross an outer cell membrane. Alternatively, intracellular reduction-oxidation activity can also be used as a measure of cell metabolic activity since such activity is also 
related to the function of the electron transport chain (hence CMP) in addition to the anabolic and catabolic activity of the cell (Haughland 2002).

In the work presented here we tried to develop a standard flow cytometry protocol for the Gram +'ve bacterium Bacillus cereus, and understand more of the resulting staining phenomena using cell sorting. Specifically the use of $\operatorname{DiOC}_{6}(3)$ and the proprietary RedoxSensor Green (an indicator of bacterial reductase activity, Molecular Probes, Invitrogen, UK) both counter stained with propidium iodide to monitor the physiological state of Bacillus cereus throughout its growth cycle. Bacillus spp. are widely used in industry for the manufacture of commercially important extracellular enzymes (mainly amylases or proteases), bioinsecticides and for aerobic waste water treatment (Reis et al., 2005). In this way it was hoped to develop a method for tracking Gram+ve bacterial physiological state that would be useful for the bioprocessing industries.

\section{MATERIALS AND METHODS}

\section{Organism and growth conditions.}

Bacillus cereus NCTC1143, an asporulating mutant, was chosen as a model organism because it is a common rod shaped, soil-dwelling bacterium that is easy to grow in the laboratory and was found in this study to be very sensitive to culture conditions. Cultures of B. cereus were grown by adding $100 \mu \mathrm{l}$ of the glycerol stock to $50 \mathrm{ml}$ nutrient broth (Oxoid, UK) without glucose, in $500 \mathrm{ml}$ baffled shake-flasks at $37{ }^{\circ} \mathrm{C}$ and $200 \mathrm{rpm}$ in an orbital shaker for $\sim 14 \mathrm{~h}$. This culture was then used to inoculate 24 similarly prepared flasks, with duplicate flasks taken periodically for analysis.

\section{Flow cytometry protocols.}

Flow cytometric analysis and cell sorting were done by a Coulter EPICS ELITE flow 
cytometer (High Wycombe, UK) with $488 \mathrm{~nm}$ excitation from an argon-ion LASER at 15 $\mathrm{mW}$. Samples taken from the culture were immediately diluted (at least 1:2000 v/v) with Dulbecco's buffered saline (DBS, $\mathrm{pH}$ 7.2) and stained with one of two mixtures of fluorescent stains either $\mathrm{PI} / \mathrm{DiOC}_{6}(3)$ or PI/RedoxSensor Green. Samples were kept in a sonication bath for $10 \mathrm{~s}$ prior to analysis, in order to reduce problems associated with cell aggregation. Individual cells were sorted directly onto nutrient agar plates (at least 100 cells on each of a minimum of 5 plates per sort) such that each cell could give rise to a discrete visible colony after 24 hours incubation at room temperature. For fluorescent microscopic examination, populations of like cells were sorted onto filter disks pre-wetted with Dulbeco's buffered saline (DBS, pH 7.2) and examined under the fluorescent microscope within 1 minute. Stock solutions of each dye were prepared as follows: $\operatorname{DiOC}_{6}(3)$ was made up at $10 \mu \mathrm{g} \cdot \mathrm{ml}^{-1}$ in dimethyl sulphoxide (DMSO), PI was made up at $2 \mathrm{mg} \cdot \mathrm{ml}^{-1}$ in distilled water and RedoxSensor Green was added at the concentration supplied by the manufacturer. The working concentrations of $\mathrm{DiOC}_{6}(3)$, RedoxSensor Green and PI were $0.3 \mu \mathrm{g} \cdot \mathrm{ml}^{-1}, 3.0 \mu \mathrm{M}$ and $0.3 \mu \mathrm{g} \cdot \mathrm{ml}^{-1}$, respectively in Dulbecco's buffered saline ( $\mathrm{pH} 7.2$, DBS). All solutions were passed through a $0.2 \mu \mathrm{m}$ filter, immediately prior to use, to remove particulate contamination. Signal discrimination was set on Forward Angle Light Scatter (FALS or FS) and Right Angle Light Scatter (RALS or SS) signal. The optical filters were set up so that PI fluorescence was measured using a $630 \mathrm{~nm}$ long pass while $\mathrm{DiOC}_{6}(3)$ and RedoxSensor Green fluorescence were measured using a $525 \mathrm{~nm}$ band pass. In all cases there was some spectral overlap between the emitted fluorescence of the stains in mixtures however, due to the large dynamic range of the signals compensation was kept to a minimum to aid cluster differentiation but to avoid overcompensation. Bacteria were identified by their light scattering cluster which was used as a gate for the fluorescence density plots. 


\section{Other analytical techniques.}

Cell growth was monitored by optical density $(580 \mathrm{~nm})$ using a double-beam spectrophotometer, with samples being diluted, with DBS, into the range 0-0.6 absorbance units prior to analysis. Microscopy was performed using a Leitz Ortholux II microscope and a 100x oil immersion objective and images were taken using a with a Nikon DS-2Mv camera.

\section{RESULTS AND DISCUSSION}

Duplicate batch fermentations of Bacillus cereus were carried out in which samples were taken periodically and stained with one of two mixtures of fluorescent stains, either $\mathrm{DiOC}_{6}(3) / \mathrm{PI}$ or RedoxSensor Green/PI, over the course of a standard growth curve (Figure 1). A $2 \mathrm{~h}$ lag phase was followed by $2 \mathrm{~h}$ of rapid growth, with a maximum specific growth rate ( $\mu$ max) of $1.02 \mathrm{~h}^{-1}$ recorded at $3 \mathrm{~h}$, after which the culture entered the stationary phase before being terminated at $24 \mathrm{~h}$. It can be seen from the $\mathrm{pH}$ curve that the initial fall, resulting from the depletion of the complex carbon-source present, was arrested after only 3 h. Following this point, the $\mathrm{pH}$ steadily and continuously rose, probably as a consequence of deamination as amino acids are consumed as a carbon source, with the rising $\mathrm{pH}$ further influencing the metabolism of the cells, the culture eventually entering the conventionally termed stationary and decline phases. This illustrates the suitability of this system as a model for evaluating fluorescent dyes in a range of physiological states for the cell population.

For samples stained with $\mathrm{DiOC}_{6}(3) / \mathrm{PI}$ the presence of up to three populations of cells could be expected. These correspond to cells with an intact depolarised cytoplasmic membrane, not stained (A), cells with an intact polarised cytoplasmic membrane, stained with 
DiOC $_{6}(3)(B)$, and cells with a permeablised depolarised cytoplasmic membrane stained with PI only (D). This was found to be true here (Figure 2) although in the case of lag/stationary phase Bacillus cereus cells a fourth sub-population was also identified (C). This corresponded to cells stained with both $\mathrm{PI}$ and $\mathrm{DiOC}_{6}(3)$; paradoxically this would mean that these cells had a permeablised but polarised cytoplasmic membrane. The presence of the fourth sub-population has been shown previously (Montfort \& Baleux 1996; Lopes da Silva et al., 2005) and it has been proposed that with lipophilic cationic carbocyanine dyes such as $\mathrm{DiOC}_{6}(3)$ non-specific energy independent binding can occur when the hydrophobic regions of the cytoplasmic membranes are exposed to relatively harsh conditions such as exposure to lethal heat, dehydration in ethanol or high concentrations of the fluorochrome. However this was not the case here. Indeed when double $\mathrm{DiOC}_{6}(3) / \mathrm{PI}$ stained cells were sorted onto a filter paper and examined under the microscope it could be seen (Figure 5) that this population was made up of doublets i.e. two cells attached together, one stained positively for PI and the other stained positively for $\mathrm{DiOC}_{6}(3)$. Due to the site of connection being along the longitudinal axis of the cells, it is likely that these doublets were the result of incomplete cell division (Haeusser \& Levin 2008) rather than cells simply 'sticking together'. This is also indicated by the fact that the cells are connected at their ends. The same events sorted onto nutrient agar plates gave rise to a colony $>65 \%$ of the time (Figure 5 ) with each colony presumably being derived from the PI negative cell, approximately the same as that derived from the $\mathrm{DiOC}_{6}(3)$ only stained population where a colony was produced $\sim 70 \%$ of the time.

For cells stained with RedoxSensor Gree/PI, the existence of three populations of cells could also be expected. These correspond to cells with an intact cytoplasmic membrane with a low reductase activity, not stained (A), cells with an intact cytoplasmic membrane with a higher reductase activity stained with RedoxSensor Green (B), and cells with a 
permeablised cytoplasmic membrane with no reductase activity stained with PI only (D). This was the case here (Figure 6) although in the case of lag/stationary phase Bacillus cereus cells a fourth sub-population could again be identified (C). This corresponds to cells stained with both PI and RedoxSensor Green; counter intuitively this would mean that cells had a permeablised cytoplasmic membrane but retained a reductase activity. Whilst this could be the case, as enzyme activity is independent of cell permeabilisation, the retention of the substrate would be less likely once the cell integrity is lost. Indeed when RedoxSensor Green and PI double stained cells were sorted onto a filter membrane and examined under the microscope it could indeed be seen (Figure 6) that this population was, again, made up of doublets i.e. two cells attached together, one stained positively for PI and the other stained positively for RedoxSensor Green. As previously observed, this subpopulation, when sorted onto nutrient agar plates gave rise to a colony $>70 \%$ of the time (Figure 6) with each colony being derived from the PI negative stained cell. This percentage was approximately the same as that derived from the RedoxSensor Green only stained population, where a colony was produced $\sim 72 \%$ of the time. For cells stained with RedoxSensor Green/PI, a fifth sub-population of cells could also be identified in the bottom corner of quadrant A. Following sorting, events did not give rise to any colonies on nutrient agar. Back gating identifies those events mainly to consist of debris by their typical meandering light scatter clustering (data not shown). Although some events scatter like bacterial cells the conclusion here is that these events were related to cell ghosts, cell debris or other particulate 'noise' (Lewis et al., 2004).

It is clear that the quality of the inoculum for the growth experiments was sub-optimal with only $\sim 28 \%$ of cells being positively stained with only either $\mathrm{DiOC}_{6}(3)$ or RedoxSensor Green at the start. In both cases within $4 \mathrm{~h}$ of inoculation almost all cells were either only DiOC6(3) or RedoxSensor Green positive, as was to be expected, because the culture had, 
by then, entered the period of most rapid growth. This remained unchanged through $8 \mathrm{~h}$ until the culture began to enter the stationary phase of growth whereupon there was a progressively detrimental change in cell physiological state until the experiment was terminated at $24 \mathrm{~h}$.

Further analysis of the cell sorting data revealed some interesting points. Unstained cells from the most rapid phase of growth when sorted directly onto nutrient agar produced a colony $>90 \%$ of the time (Figure 4). Therefore it can be concluded that passage through the flow cell and laser at $15 \mathrm{~mW}$ had little detrimental effect on the reproductive viability of the cells. Whilst in the absence of staining it is not possible to eliminate interfering particles by the absence of dye uptake, it is to be noted that a $100 \%$ recovery of cells on the nutrient agar plate should not be expected since cells only divide when conditions are absolutely perfect such that sub-lethally injured and other so called 'viable but non culturable' cells are often missed (Hewitt \& Nebe-von-Caron 2004) unless the right artificial growth medium is employed. Indeed a $3 \log$ difference in the number of cells recovered from the same Salmonella spp. sample has been observed dependent on the type of solid agar medium used (Nebe-von-Caron \& Badley 1995). When cells from the most rapid phase of growth, stained only with $\mathrm{DiOC}_{6}(3)$ were sorted based on light scatter only, a colony was produced $>99 \%$ of the time and when stained only with RedoxSensor Green $>90 \%$ of the time (Figure 4) implying that positive staining with $\mathrm{DiOC}_{6}(3)$ somehow increased the ability of cell to produce a colony on nutrient agar. Why this is so is not clear and will need further investigation. Closer examination of the data reveals that cells positively stained with either $\mathrm{DiOC}_{6}(3)$ or RedoxSensor Green taken from the phase of most rapid growth gave rise to a colony $\sim 95 \%$ of the time, almost $3 x$ as often as cells $(\sim 30 \%)$ stained positively with either fluorochrome during the lag phase of growth. This demonstrates that a cell's future ability to grow and divide is not contingent on having a higher intracellular 
reductase activity or a polarised cytoplasmic membrane. Indeed, the fact that $>40 \%$ of cells unstained with $\mathrm{DiOC}_{6}(3) / \mathrm{PI}$ and $>85 \%$ unstained with RedoxSensor Green/PI gave rise to a colony when sorted onto nutrient agar shows that an absence of a detectable cytoplasmic membrane potential or reductase activity is not sufficient to render cells incapable of future growth and division. Further, that since it is impossible for a cell to replicate without a cytoplasmic membrane potential or any reductase capability then their absence must be reversible or a staining artefact to be challenged by further staining methods, as cells would be unable to divide on the nutrient agar.

Closer examination of the colonies derived from sorted cells highlights another level of heterogeneity. Colonies of varying size appear on all of the sorts, implying variations in lag time, as it is unlikely that the cells have altered their growth rate. In all cases cells stained only with PI when sorted onto nutrient agar did not produce a colony implying that under the conditions investigated here the cells staining with PI only are dead.

\section{CONCLUSION}

Recently, we have attempted to develop a universal dual staining technique, suitable for all bacterial cell types, to be used in the measurement by multi-parameter flow cytometry of bacterial cell physiological state during the course of various types of commercially important bioprocesses. This has proved difficult because of the difference in magnitude of membrane potential between Gram +ve and Gram -ve cells and the hindrance to entry of fluorchromes presented by the additional, outer membrane in the latter. However, the conclusion from this study (and informed by our previous work) is that the dual staining combination with $\mathrm{PI} / \mathrm{DiOC}_{6}(3)$ is likely to be suitable for use with the Gram +ve cells e.g. Bacillis cereus, Bacillus licheniformis, Corynebacter glutamicum, Rhodococcus spp, 
(Lopes da silva et al., 2005; Chamsartra et al., 2005; Amanullah et al., 2002) and the dual staining combination with PI/bisoxanol is suitable for Gram -ve cells e.g. E. coli, Salmonella spp., Acinetobacter johnsonii (Boswell et al., 1998; Want et al., 2009.; Hewitt \& Nebe-von-Caron 2001; Nebe-von-Caron et al., 2000; Boswell et al., 1998). This is likely to be species and process specific whilst the interpretation of such data can only be reliably made when the necessary control experiments have been carried out properly. Whilst progressive differential staining of cells is observed throughout a growth curve with RedoxSensor Green the interpretation of the data is difficult because the identity and exact mode of action of the stain remains unknown.

It is recognised that the relatively complex and high cost of quantitative fluorescent microscopy or flow cytometry equipment, when compared with other more traditional microbiological techniques, has prohibited it from becoming a routine analytical tool for use in most microbiology laboratories. Nevertheless, the data presented here has identified at least 4 distinguishable physiological states with the two staining protocols alone, highlighting further the unexpectedly complex population dynamics of bacterial cultures. This lays to rest the microbiological dogma that all bacterial cells in a culture behave in exactly the same homogenous way; they are clearly members of a physiologically heterogenous population. Such a conclusion, if correct, could cast doubt on the interpretation of many 'omic array' analyses which assume a population of bacterial cells to be homogeneous with respect to their physiological state. 


\section{NOMENCLATURE}

$\psi \quad$ Electro potential

i Inside,

o Outside,

a Active (diffusible or unbound) concentration,

R Universal gas constant,

T Absolute temperature,

z Charge,

F Faraday constant

\section{ACKNOWLEDGMENTS}

Fluorochromes were provided by Molecular Probes/Invitrogen (Oregon, USA) and the authors thank William Godfrey (Invitrogen Corporation) for his helpful discussions. The authors would like to acknowledge the financial support of the Biotechnology and Biological Sciences Research Council (UK), Avecia Biologics Ltd (UK) and Novozymes A/S (Denmark) for this study.

\section{REFERENCES}

Amanullah, A., Hewitt, C. J., Nienow, A. W., Lee, C., Chartrain, M., Buckland, B., Drew, S. \& Woodley, J. (2002) Measurement of Strain Dependent Toxicity in the Indene Bioconversion using Multi-parameter Flow Cytometry. Biotechnol Bioeng 80, 239-249.

Boswell, C. D., Hewitt, C. J. \& Mackaskie L. E. (1998) An application of bacterial flow cytometry: Evaluation of the toxic effects of four heavy metals on Acinetobacter sp. with potential for bioremediation of contaminated wastewaters. Biotechnol Lett 20, 857-863. 
Chamsartra, S., Hewitt, C. J. \&Nienow, A. W. (2005) The impact of fluid mechanical stress on Corynebacterium glutamicum during continuous cultivation in an agitated bioreactor. Biotechnol Lett 27, $693-700$.

Davey, H. M. \& Kell, D. B. (1996) Flow cytometry and cell sorting of heterogeneous microbial populations: the importance of single-cell analyses. Microbiol Rev 60, 641-\&.

Haeusser, D.P. \& Levin, P.A. (2008) The great divide: coordinating cell cycle events during bacterial growth and division. Curr Opin Microbiol 11, 94 - 99.

Haugland, R.P. (2002) Handbook of Fluorescent Probes and Research Chemicals. Molecular Probes, Eugene, OR, USA.

Hewitt, C. J., Boon, L. A., McFarlane, C. M \& Nienow A. W. (1998) The use of flow cytometry to study the impact of fluid mechanical stress on E. coli during continuous cultivation in an agitated bioreactor. Biotechnol Bioeng 59, 612-620.

Hewitt, C. J., Nebe-von Caron, G., Nienow, A. W. \& McFarlane C. M. (1999) The use of multi-parameter flow cytometry to compare the physiological response of Escherichia coli W3110 to glucose limitation during batch, fed-batch and continuous culture cultivation. $J$ Biotechnol 75, 251-254..

Hewitt C. J. \& Nebe-von-Caron G. (2001) An industrial application of multi-parameter flow cytometry: Assessment of cell physiological state and its application to the study of microbial fermentations. Cytometry 44, 179-187.

Hewitt, C. J. \& Nebe-von-Caron, G. (2004) The application of multi-parameter flow 
cytometry to monitor individual microbial cell physiological state. Adv Biochem Eng Biot 89, $197-223$.

Hewitt, C. J. \& Nienow, A. W. (2007) The scale-up of microbial batch and fed-batch fermentation processes. Adv Appl Microbiol 62, 105-135.

Jepras, R.I., Paul, F.E., Pearson, S.C., \& Wilkinson M.J. (1997) Rapid assessment of antibiotic effects on E. coli by bis-(1,3-dibutylbarbituric acid) trimethine oxonol and flow cytometry. Antimicrob Agents Ch 41, 2001-2005.

Lewis, G., Taylor, I. W., Nienow, A. W. \& Hewitt C. J. (2004) The application of multiparameter flow cytometry to the study of recombinant Escherichia coli batch fermentation processes. J Ind Microbiol Biot 31, 311 -322

Lopes da Silva, T., Reis, A., Kent, C. A., Kosseva, M., Roseiro, J. C. \& Hewitt, C. J. (2005) Stress-induced physiological responses to glucose and lactose pulses in Bacillus licheniformis continuous culture fermentation processes as measured by multi-parameter flow cytometry. Biochem Eng $J$ 24, 31-41.

Monfort, P. \& Baleux, B. (1996) Cell cycle characteristics and changes in membrane potential during growth of Escherichia coli as determined by cyanine fluorescent dye and flow cytometry. J Microbiol Meth 25, 79-86.

Müller, S., N. Loffhagen, T. Bley, \& W. Babel. (1996) Membrane-potential-related fluorescence intensity indicates membrane injury. Microbiol Res 151, 127- 131 
Nebe-von-Caron, G. \& Badley, R.A. (1995) Viability assessment of bacteria in mixed populations using flow-cytometry. J Microsc-Oxford 179, 55-66.

Nebe-von-Caron, G. \& Mueller, S. 2007 Bugs In The Beam, In Cytometry 10, Edited by J.P.Robinson, MMK Holdings, ISBN 978-1-890473-10-5

Nebe-von-Caron, G., Stephens, P. J., Hewitt, C. J. , Powell, J. R. \& Badley ,R. A. (2000) Analysis of bacterial function by multi-colour and single cell sorting. J Microbiol Meth $\mathbf{4 2}$, 97-114.

Reis, A., Lopes da Silva, T., Kent, C. A., Kosseva, M., Roseiro, J. C. \& Hewitt, C. J. (2005) The use of multi-parameter flow cytometry to study the impact of limiting substrate, agitation intensity and dilution rate on Bacillus licheniformis CCMI 1034 aerobic continuous culture fermentations. Biotechnol Bioeng 92, $568-578$.

Sebastine, I.M., Stocks, S. M., Cox, P. W. \& Thomas C. R. (1999). Characterisation of percentage viability of Streptomyces clavuligerus using image analysis. Biotechnol Tech 13, 419-423.

Shapiro, H.M., (2003) Practical Flow Cytometry, 4th Edn, Alan R. Liss Inc. New York.

Shi, L., Günther, S., Hübschmann, T., Wick, L.Y., Harms, H. \& Müller, S. (2007) Limits of propidium iodide as a cell viability indicator for environmental bacteria. Cytometry $\mathbf{7 1}$, 592-598.

Stocks, S. M. \& Thomas C. R., (2001) Viability, strength, and fragmentation of accharopolyspora erythraea in submerged fermentation. Biotechnol Bioeng 75, 702-709. 
Want A., Thomas, O.R.T., Kara, B., Liddell, J. \& Hewitt C. J. (2009) Studies related to the production of antibody fragments (Fabs) in Escherichia coli W3110 fed-batch fermentation processes using multi-parameter flow cytometry. Cytometry $\mathbf{7 5}, 148-154$. 


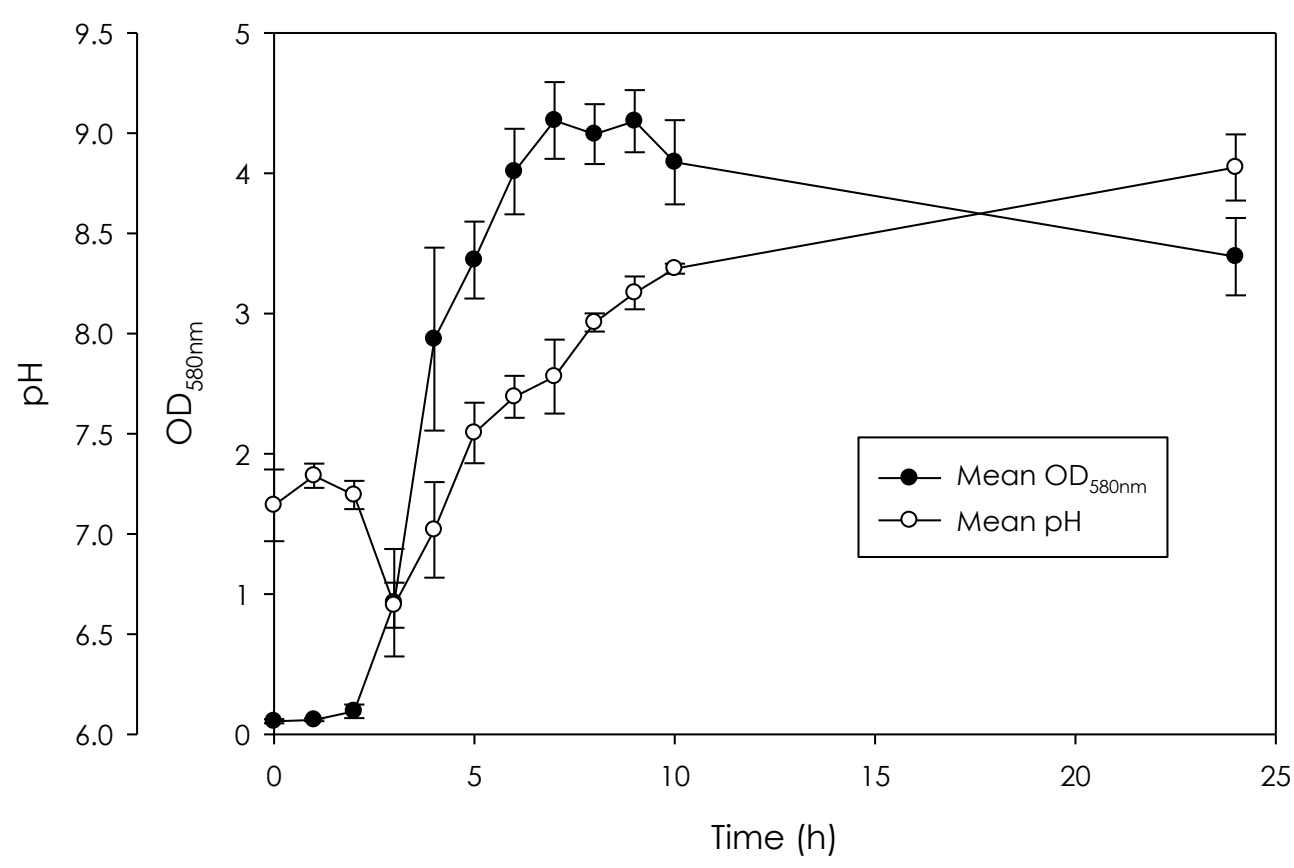

Figure 1. 

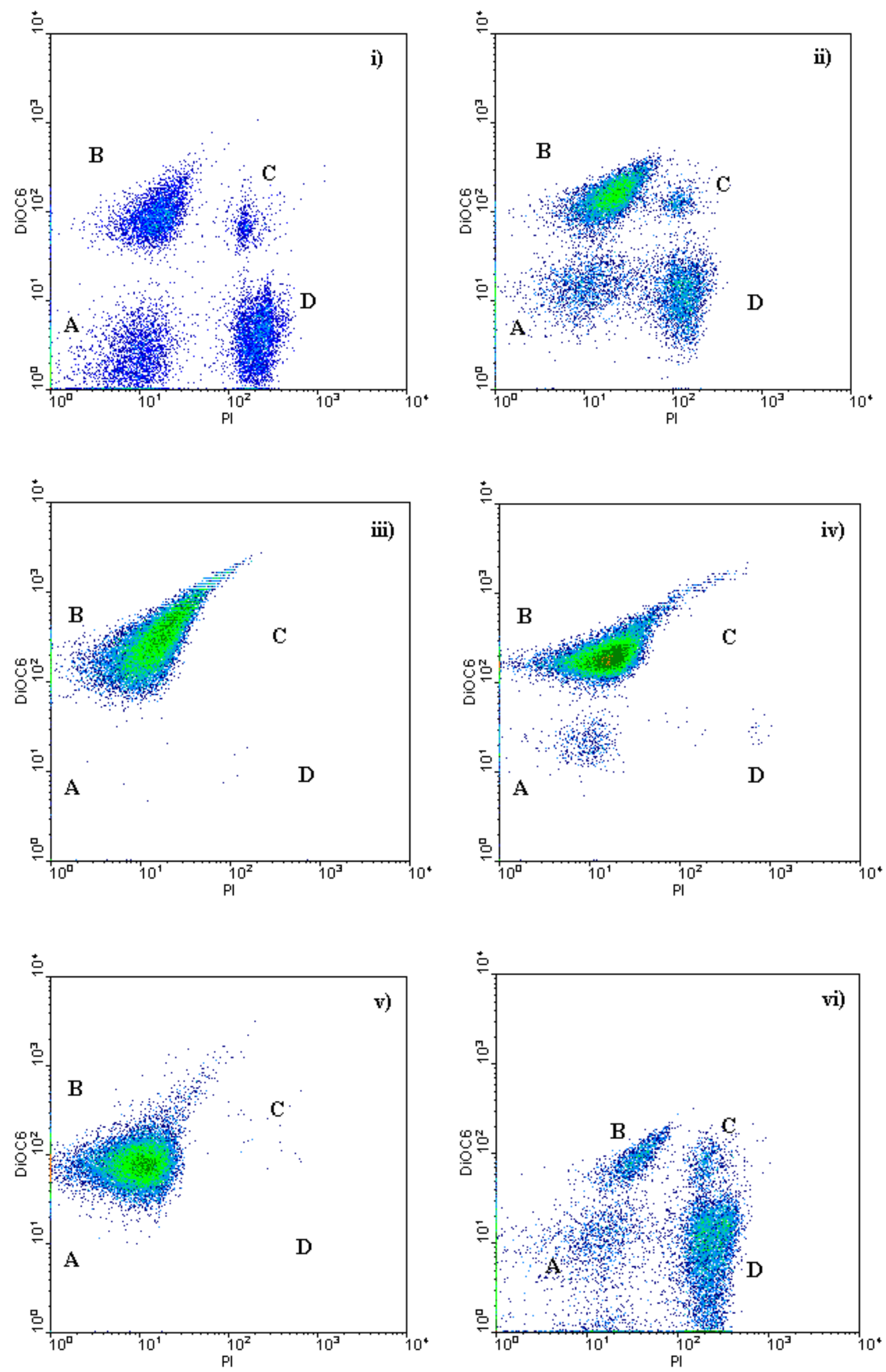

Figure 2 

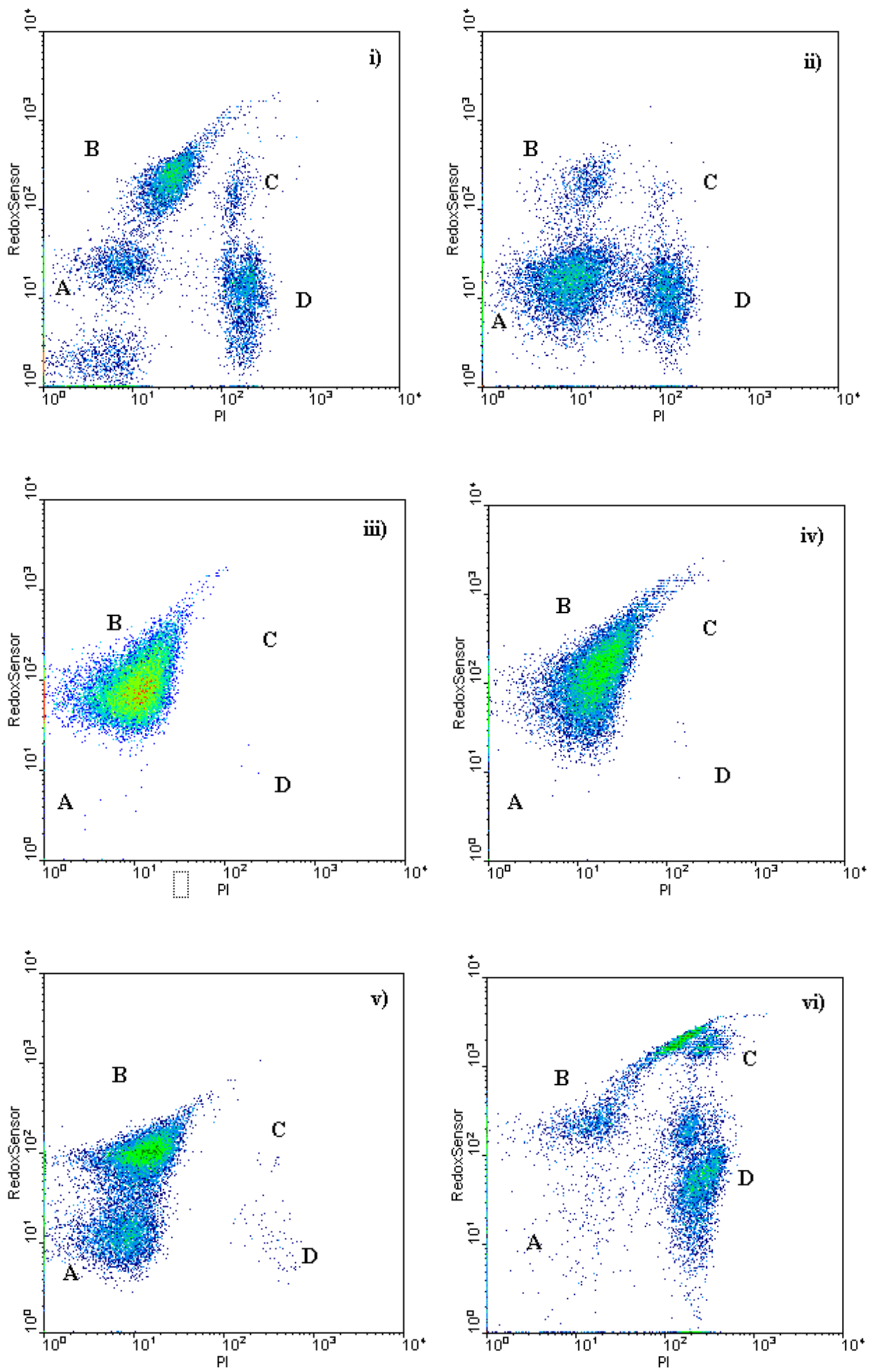

Figure 3. 


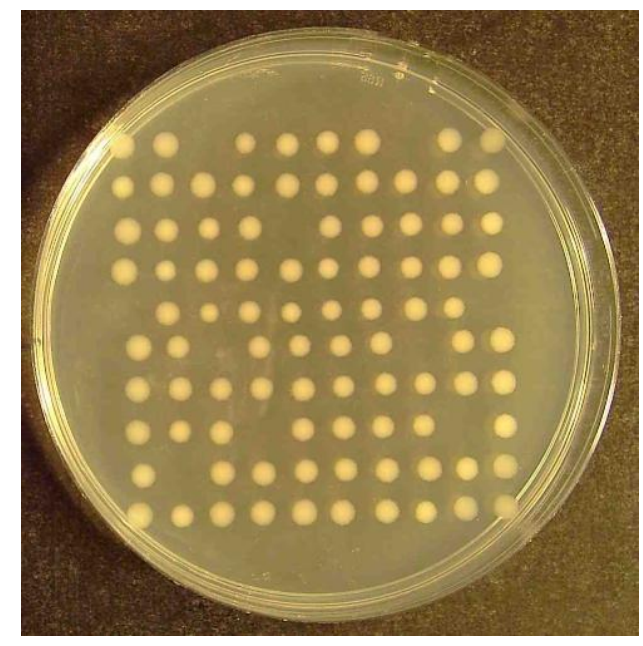

i)
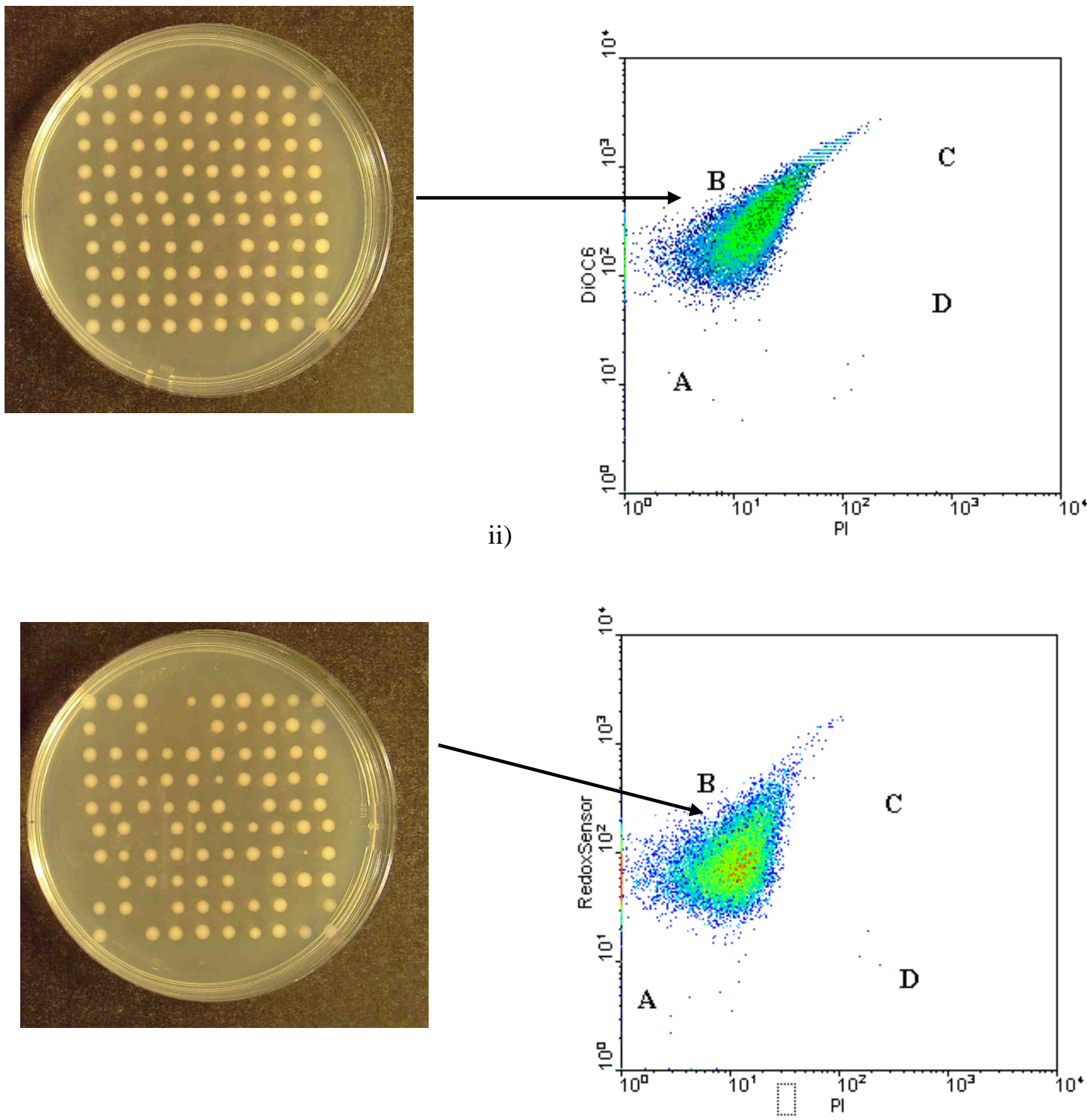

iii)

Figure 4 

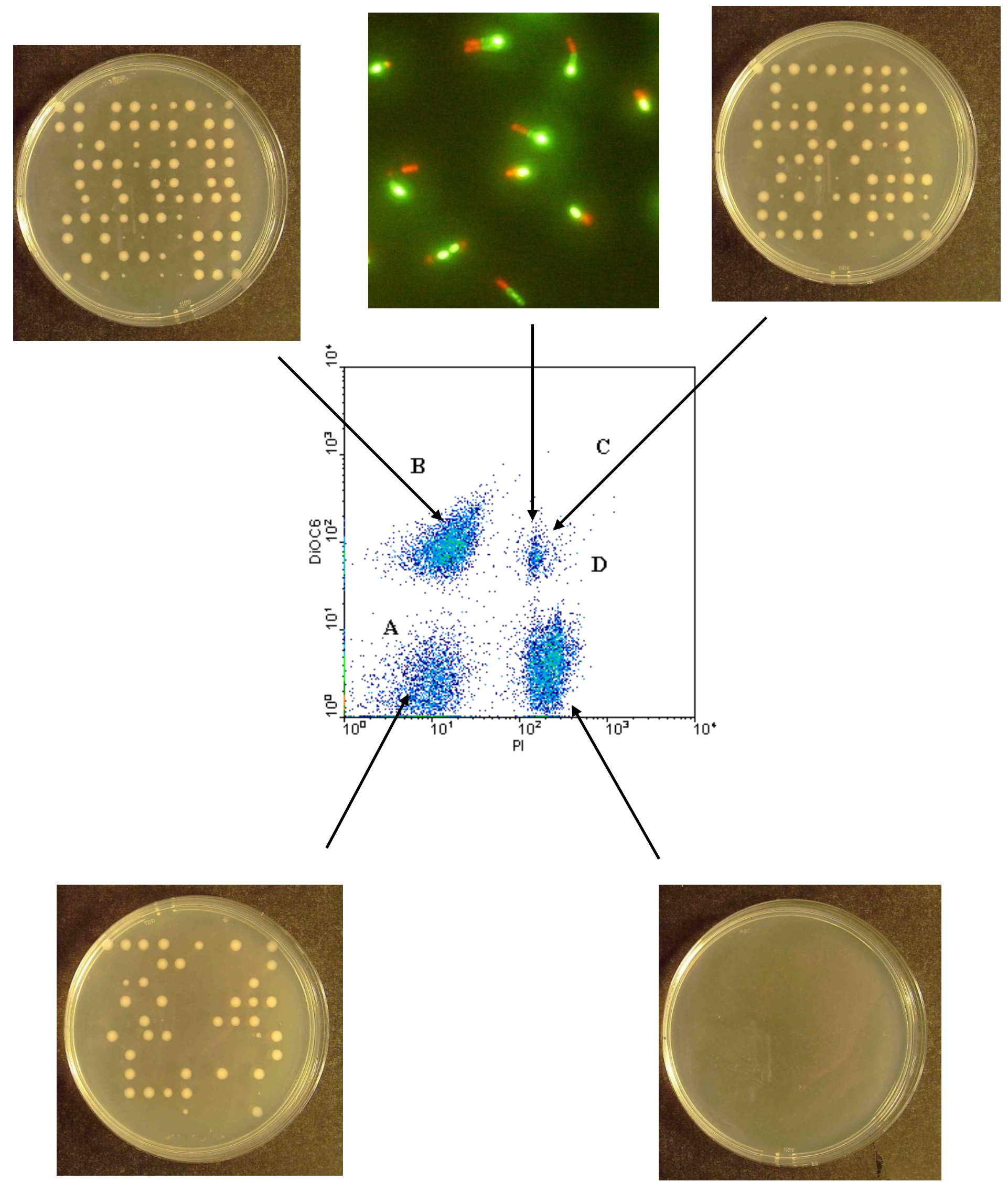

Figure 5 

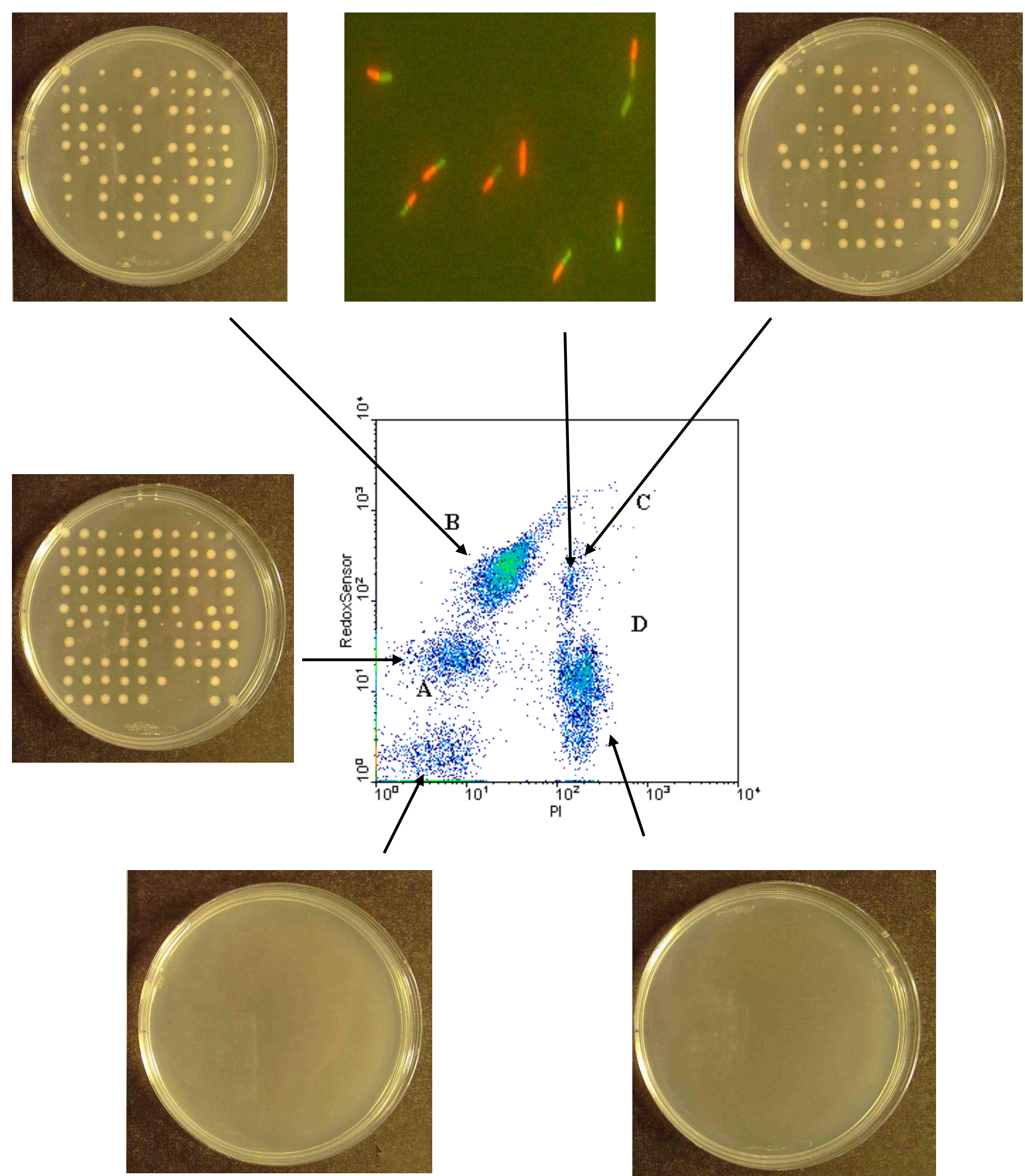

Figure 6 
Figure 1. Optical density $\left(\mathrm{OD}_{580 \mathrm{~nm}}\right)$ and $\mathrm{pH}$ profiles show mean values for four replicate 24 h batch fermentations with Bacillus cereus. Error bars show the standard deviation of the data used to calculate the mean values (minimum 14 measurements).

Figure 2. Flow cytometric analysis of cell samples taken i) pre-inoculation then at ii) $2 \mathrm{~h}$, iii) $4 \mathrm{~h}$, iv) $8 \mathrm{~h}$, v) $9 \mathrm{~h}$ and vi) $24 \mathrm{~h}$ post inoculation during the course of a $24 \mathrm{~h}$ batch fermentation with Bacillus cereus stained with $\mathrm{DiOC}_{6}(3) / \mathrm{PI}$. Up to four populations of cells could be identified. These correspond to cells with an intact depolarised cytoplasmic membrane, not stained (A), cells with an intact polarised cytoplasmic membrane, stained with $\mathrm{DiOC}_{6}(3)(\mathrm{B})$, cells with a permeablised depolarised cytoplasmic membrane stained with PI only (D), and cells stained with both PI and $\mathrm{DiOC}_{6}(3)(\mathrm{C})$.

Figure 3. Flow cytometric analysis of cell samples taken i) pre-inoculation then at ii) $2 \mathrm{~h}$, iii) $4 \mathrm{~h}$, iv) $8 \mathrm{~h}$, v) $9 \mathrm{~h}$ and vi) $24 \mathrm{~h}$ post inoculation during the course of a $24 \mathrm{~h}$ batch fermentation with Bacillus cereus stained with RedoxSensor Green/PI. Up to four populations of cells could be identified. These correspond to cells with an intact cytoplasmic membrane with a low reductase activity, not stained (A) cells with an intact cytoplasmic membrane with a higher reductase activity stained with RedoxSensor Green (B), cells with a permeablised cytoplasmic membrane with no reductase activity stained with PI only (D) and cells stained with both PI and RedoxSensor Green (C).

Figure 4. Functional assessment i) unstained, ii) stained with DiOC6(3)/PI, iii) RedoxSensor Green/PI and cell sorting. Rapid growth phase cells of Bacillus cereus i.e. $4 \mathrm{~h}$ after inoculation sorted directly onto Nutrient Agar plates.

Figure 5. Functional assessment by multicolour staining with $\mathrm{DiOC}_{6}(3) / \mathrm{PI}$ and cell sorting. 
Lag phase cells of Bacillus cereus i.e. $2 \mathrm{~h}$ after inoculation stained and sorted directly onto Nutrient Agar plates.

Figure 6. Functional assessment by multicolour staining with RedoxSensor Green/PI and cell sorting. Lag phase cells of Bacillus cereus i.e. $2 \mathrm{~h}$ after inoculation stained and sorted directly onto Nutrient Agar plates. 